\title{
Fatigue Strength Characteristics of High-Strength Steel ${ }^{*}$
}

\author{
Katsutoshi ASAMI** and Hideki EMURA**
}

\begin{abstract}
In order to clarify the fatigue strength characteristics of low-alloy steels tempered at low temperature $\left(150 \sim 200^{\circ} \mathrm{C}\right)$ or carburized in generated gas, rotating bending fatigue tests were conducted in laboratory air and dry air. The influence of moisture in air was only observed for the carburized steel. The low-temperature-tempered steel revealed two knees on the $\mathrm{S}-\mathrm{N}$ diagram, and no fatigue limit was found up to $10^{9}$ cycles ( 9 months). The carburized steel revealed three knees and the fatigue limit was found over $10^{8}$ cycles. When the fatigue test of carburized steel was carried out in dry air or the surface structure anomalies were removed, the fatigue strengths were improved, but neither knees nor fatigue limits were found up to $10^{9}$ cycles. The reasons for this were discovered from the results of fractography and the equations proposed by Murakami et al. for the prediction of the fatigue limit of steel with microdefects.
\end{abstract}

Key Words: Fatigue, S-N Curve, Fatigue Limit, High-Strength Steel, Low-Temperature Tempering, Carburizing, Fish-Eye Fracture, Inclusion, Moisture, Vickers Hardness

\section{Introduction}

Low-temperature tempering and carburizing are often used as simple means of obtaining high-strength steels. The fatigue strength characteristics of lowtemperature-tempered or carburized steels in the long life range over $10^{7}$ cycles, however, have hardly been clarifled $^{(1)-(4)}$. On the other hand, since mechanical properties of high-strength steels are sensitive to environmemt, it is anticipated that even moisture in the air may influence those fatigue strength characteristics. Studies on this problem are also very few in number.

This study, therefore, aims to clarify the fatigue strength characteristics of low-alloy steels tempered at low temperature or carburized in generated gas, with particular attention paid to the long life range over $10^{7}$ cycles and the influence of moisture in air.

* Received 7th November, 1989. Paper No. 88-0413B

** Department of Mechanical Engineering, Musashi Institute of Technology, 1-28-1 Tamazutumi, Setagaya-ku, Tokyo, 158, Japan

\section{Materials and procedure}

Steels tempered at low temperatures were JIS SCM 435 (two charges, A and B) and SNCM 439, the chemical cimpositions for which are shown in Table 1. For the purpose of comparison, those tempered at high temperature (conventional tempering temperature) were also made available. The heat treatment conditions and the mechanlcal properties after the heat treatments are shown in Fig. 1 and Table 2, respectively. The tensile strengths of steels tempered at low temperatures were at least twice those of the steels tempered at high temperature.

Steels carburized in generated gas with $0.8 \%$ carbon potential were JIS SCM 420 and SNCM 420 ,

Table 1 Chemical compositions of $\mathrm{Cr}-\mathrm{Mo}$ steel (JIS SCM 435) and Ni-Cr-Mo steel (JIS SNCM 439)

\begin{tabular}{|c|c|c|c|c|c|c|c|c|c|}
\hline \multicolumn{2}{|c|}{ Material } & $\mathrm{C}$ & $\mathrm{Si}$ & Mn & $\mathrm{P}$ & $\mathrm{S}$ & $\mathrm{Cr}$ & Mo & $\mathrm{Ni}$ \\
\hline SCM4355 & $\mathrm{A}$ & 0.36 & 0.20 & 0.82 & 0.013 & 0.007 & 1.10 & 0.16 & - \\
\cline { 2 - 9 } & $\mathrm{B}$ & 0.38 & 0.27 & 0.80 & 0.015 & 0.012 & 1.07 & 0.17 & - \\
\hline SNCM439 & 0.38 & 0.27 & 0.68 & 0.010 & 0.010 & 0.75 & 0.19 & 1.72 \\
\hline
\end{tabular}


Table 2 Mechanical properties of low/high-temperature-tempered $\mathrm{Cr}$-Mo steel (JIS SCM 435) and Ni-Cr-Mo steel (JIS SNCM 439)

\begin{tabular}{|c|c|c|c|c|c|c|}
\hline & \multicolumn{4}{|c|}{ SCM435 } & \multicolumn{2}{|c|}{ SNCM439 } \\
\hline & \multicolumn{2}{|c|}{$150^{\circ} \mathrm{C}$} & \multicolumn{2}{|c|}{$600^{\circ} \mathrm{C}$} & $200^{\circ} \mathrm{C}$ & $600^{\circ} \mathrm{C}$ \\
\hline Yield Point & 1411 & 1515 & 902 & 947 & 1440 & 924 \\
\hline Tensile Strength(MPa) & 1910 & 2122 & 972 & 1031 & 1970 & 1040 \\
\hline Elongation & 11.5 & 10.3 & 19.3 & 18.8 & 11.0 & 17.5 \\
\hline Reduction of Area (\%) & 49.0 & 43.8 & 69.4 & 57.3 & 43.5 & 54.6 \\
\hline Hardness HV & 529 & 555 & 306 & 314 & 562 & 327 \\
\hline
\end{tabular}

Table 3 Chemical compositions of $\mathrm{Cr}$-Mo steel (JIS SCM 420) and Ni-Cr-Mo steel (JIS SNCM 420)

\begin{tabular}{|l|c|c|c|c|c|c|c|c|c|}
\hline Material & $\mathrm{C}$ & $\mathrm{Si}$ & $\mathrm{Mn}$ & $\mathrm{P}$ & $\mathrm{S}$ & $\mathrm{Cu}$ & $\mathrm{Ni}$ & $\mathrm{Cr}$ & Mo \\
\hline SCM420 & 0.22 & 0.27 & 0.75 & 0.016 & 0.020 & 0.16 & 0.11 & 1.05 & 0.16 \\
\hline SNCM420 & 0.20 & 0.30 & 0.55 & 0.015 & 0.013 & 0.14 & 1.64 & 0.53 & 0.16 \\
\hline
\end{tabular}

Quenching

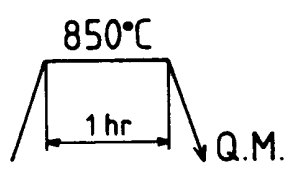

Quenching

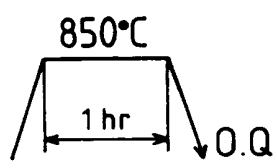

Tempering

Tempering

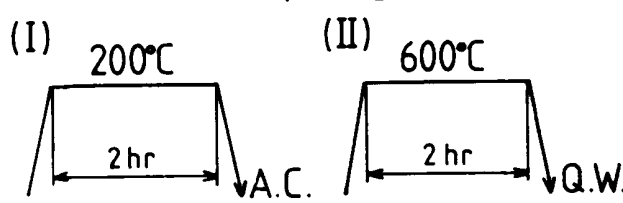

SNCM 439

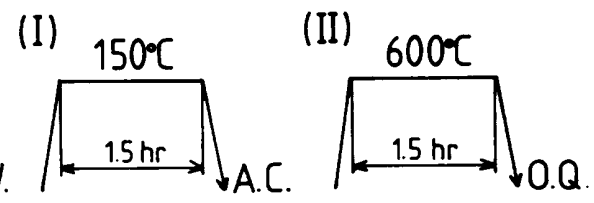

SCM 435

Fig. 1 Conditions of low/high temperature tempering heat treatment

the chemical compositions of which are shown in Table 3. The conditions of carburizing, quenching and tempering are shown in Fig. 2. The Vickers hardness distributions after these heat treatments are shown in Fig. 3. The hardness values near the surfaces of both steels decreased, because of the presence of surface structure anomalies which consisted of internal oxides (about $8 \mu \mathrm{m}$ in depth) and nonmartensitic microstructures (about $30 \mu \mathrm{m}$ in depth). The effective case depth based on the hardness of $550 \mathrm{HV}$ was about 0.8 $\mathrm{mm}$ for both steels, while the total case depth was $1.4 \mathrm{~mm}$ or so for SCM420 steel, and about $1.6 \mathrm{~mm}$ for SNCM 420 steel.

The design of the fatigue specimen used in this study is shown in Fig. 4. Tempered specimens were finished by polishing with emery paper after the heat treatments, while carburized specimens were finished before the heat treatments. The surface layer of some
Carburizing and Quenching

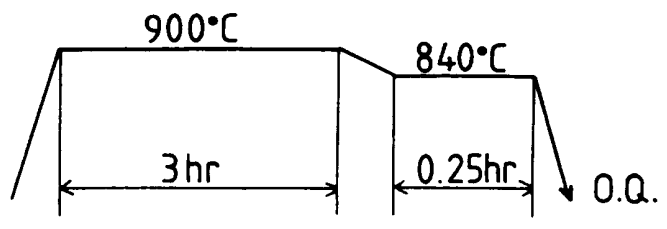

Tempering

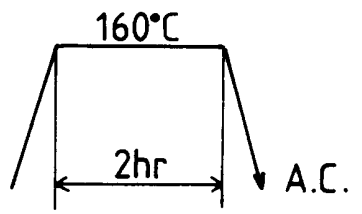

Fig. 2 Condition of carburizing heat treatment 
carburized specimens was ground off to a depth of $0.1 \mathrm{~mm}$, in order to find the influence of surface structure anomalies on the fatigue strength characteristics.

Rotating bending fatigue machines of $98 \mathrm{~N} \cdot \mathrm{m}$ in load capacity and $2850 \mathrm{rpm}$ in cyclic speed were used for the fatigue tests, which were carried out in laboratory air. Furthermore, the tempered SNCM 439 specimen, and the carburized SCM 420 and SNCM 420 specimens were also tested in dry air whose dew point was about $-70^{\circ} \mathrm{C}$, in order to clarify the influence of moisture in air on the fatigue strength characteristics. The apparatus shown in Fig. 5 was constructed so that the air would become dry only at the portion to be tested.

Fractographic features near the fracture origins were observed by a scanning electron microscope.

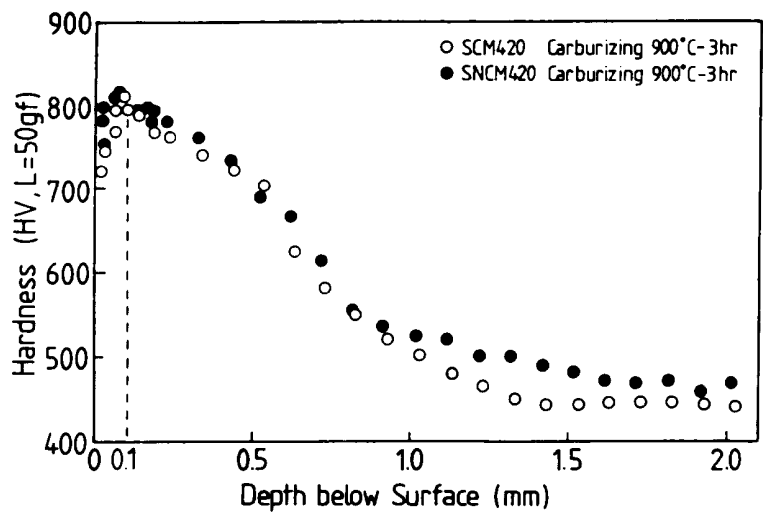

Fig. 3 Vickers hardness distributions of carburized steels

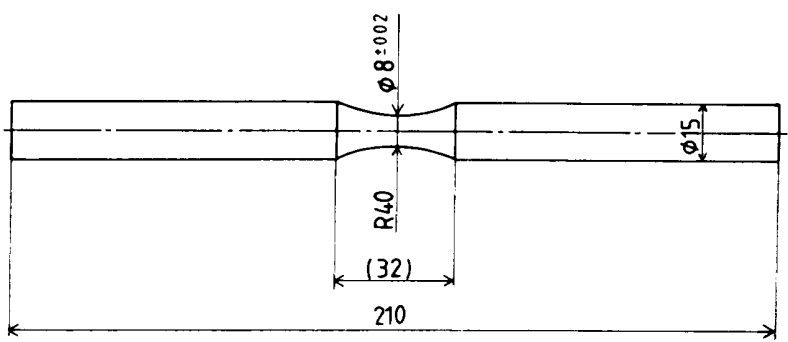

Fig. 4 Shape and dimensions of fatigue test specimen

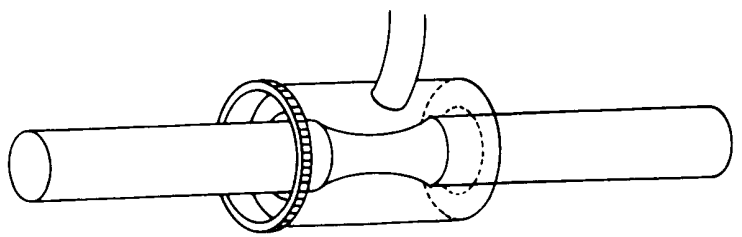

Fig. 5 Appearance of fatigue test in dry air

\section{Experimental results}

\section{1 Low-temperature-tempered steels}

3.1.1 SCM 435 Results of fatigue tests are shown in Fig. 6. In the case of specimens tempered at $600^{\circ} \mathrm{C}$ (high tempering temperature), the forms of S$\mathrm{N}$ diagrams were normal for both charge $\mathrm{A}$ and $\mathrm{B}$ specimens. The fatigue limits were about $480 \mathrm{MPa}$ and $510 \mathrm{MPa}$, respectively. In the case of the specimens tempered at $150^{\circ} \mathrm{C}$ (low tempering temperature), on the other hand, the forms of S-N diagrams were markedly different from those of the $600^{\circ} \mathrm{C}$ tempered specimens. That is, two knees were recognized on the S-N diagrams, which dropped linearly even in the long life range over $10^{7}$ cycles, without fatigue limits up to $3 \times 10^{8}$ cycles. Moreover, it should be noted that large scatters were found on the fatigue strengths.

3.1.2 SNCM 499 Results of fatigue tests are shown in Fig. 7. In the case of specimens tempered at

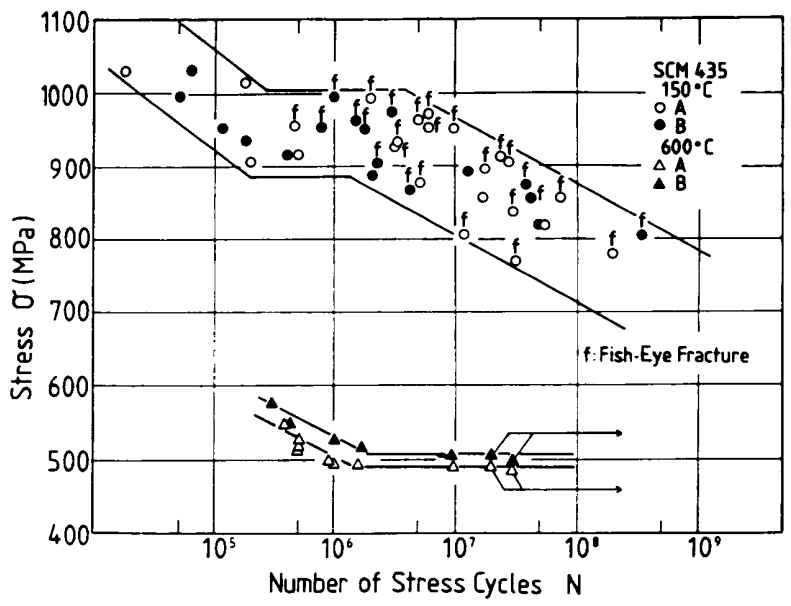

Fig. 6 S-N diagrams of low/high-temperature-tempered SCM 435 steels

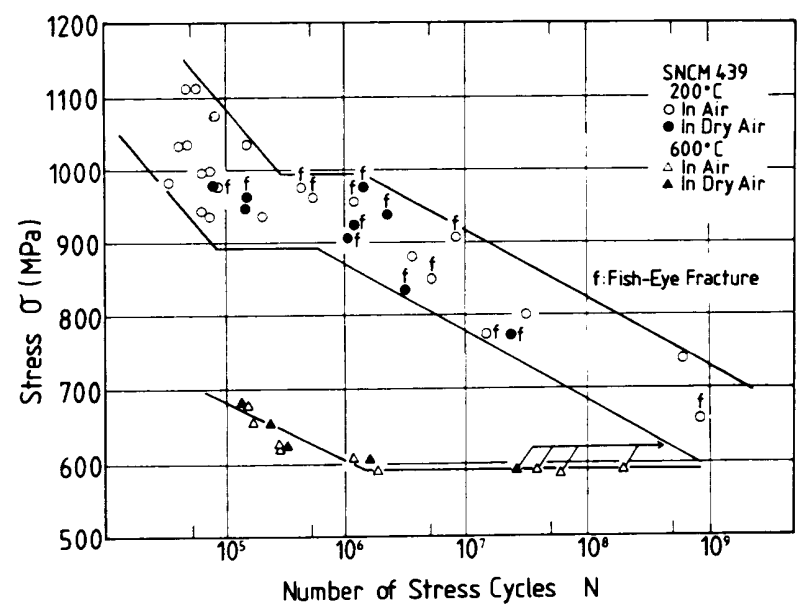

Fig. 7 S-N diagrams of low/high temperature tempered SNCM 439 steels 
$600^{\circ} \mathrm{C}$, the form of the S-N diagram was normal and the fatigue limit was about $580 \mathrm{MPa}$. In the case of specimens tempered at $200^{\circ} \mathrm{C}$, the presence of two knees and the large scatter of fatigue strength were similar to the results of the SCM $435150^{\circ} \mathrm{C}$-tempered specimen, and no fatigue limit was found up to about $10^{9}$ cycles.

No obvious difference was recognized in the results between laboratory air and dry air. Consequently, it is said that moisture in air does not influence fatigue strengths of steels tempered at low or high temperatures.

\section{2 Garburized steels}

3.2.1 SCM 420 Results of fatigue tests are shown in Fig. 8. The S-N diagram of the as-carbur. ized specimen revealed three knees on the curve, and the third knee, which was found at about $10^{8}$ cycles, corresponded to the fatigue limit. The value $(500$ to $560 \mathrm{MPa}$ ) of the fatigue limit was nearly the same as those $(480 \sim 600 \mathrm{MPa})$ of high-temperature-tempered specimens.

The fatigue strength of the ground-off specimen without surface structure anomalies became higher than that of the as-carburized specimen with surface structure anomalies, but neither knee nor fatigue limit in the $\mathrm{S}-\mathrm{N}$ diagram was found up to about $10^{9}$ cycles. It should be noted that the ground-off specimen to which cyclic stress of $1060 \mathrm{MPa}$ was applied did not fail up to $3.5 \times 10^{8}$ cycles. The reason will be discussed later on.

In the short life range up to $10^{5}$ cycles (the first knee), no obvious difference was recognized in the results between laboratory air and dry air on the fatigue strength of the as-carburlzed specimen. When the number of stress cycles exceeded $10^{6}$ cycles (the second knee), the fatigue strength in dry air became higher than that in laboratory air, and then coincided with that of ground-off specimens tested in laboratory

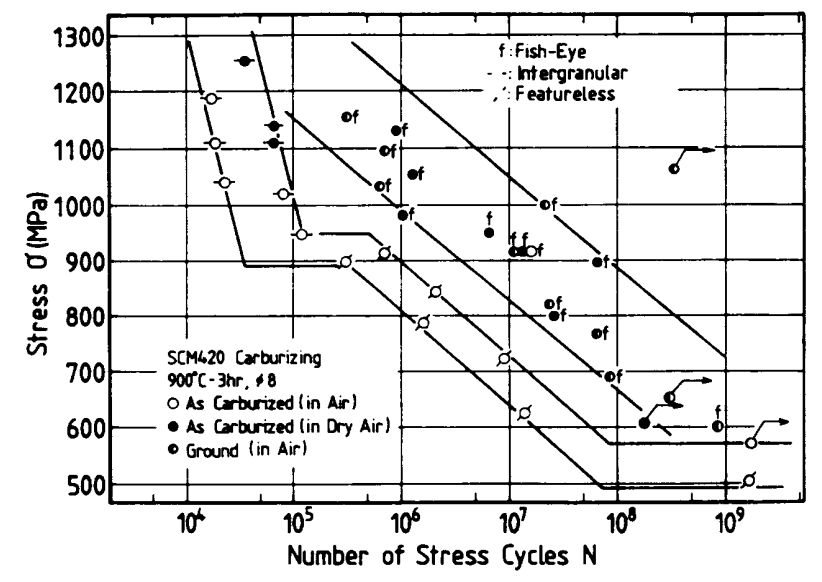

Fig. 8 S-N diagrams of carburized SCM 420 steels air. The reason will also be discussed later.

3. 2.2 SNCM 420 Results of fatigue tests are shown in Fig. 9. The fatigue strength characteristics are similar to those of SCM 420 steel given above.

\section{Discussion}

\section{1 Low-temperature-tempered steels}

As described in section 3.1, the fatigue strength characteristics of low-temperature-tempered specimens were markedly different from those of hightemperature-tempered specimens. Namely, (1) two knees were recognized in the S-N diagrams, (2) which dropped linearly even in the long life range over $10^{7}$ cycles, ( 3 ) without obvious fatigue limits in the test range up to $10^{9}$ cycles, and (4) with large scatters of fatigue strength.

Observation results of fracture surfaces revealed that the fractures in the low-temperature-tempered specimens in the short life range up to the first knee had surface origins, while those in the long life range over the second knee mainly had subsurface origins. In the case of subsurface origin (fish-eye-type fracture), the mark " $f$ " was added to each test point in Figs. 6 and 7. Consequently, it is concluded that the phenomenon mentioned in (1) was induced by the difference of location of fracture origin.

An example of fish-eye-type fracture surfaces is shown in Fig. 10. A nonmetallic inclusion was observed at the fracture origin, and it is clear that the inclusion became the initiation of fatigue fracture. Therefore, it seems that the inclusion was related to the phenomena mentioned in (2) to (4).

Furthermore, the crucial problem is that the fatigue limits of low-temperature-tempered specimens may become lower than those of high-temperature tempered specimens. This problem will be investigated according to the following equation ${ }^{(5)}$ proposed by Murakami and Endo for the prediction of

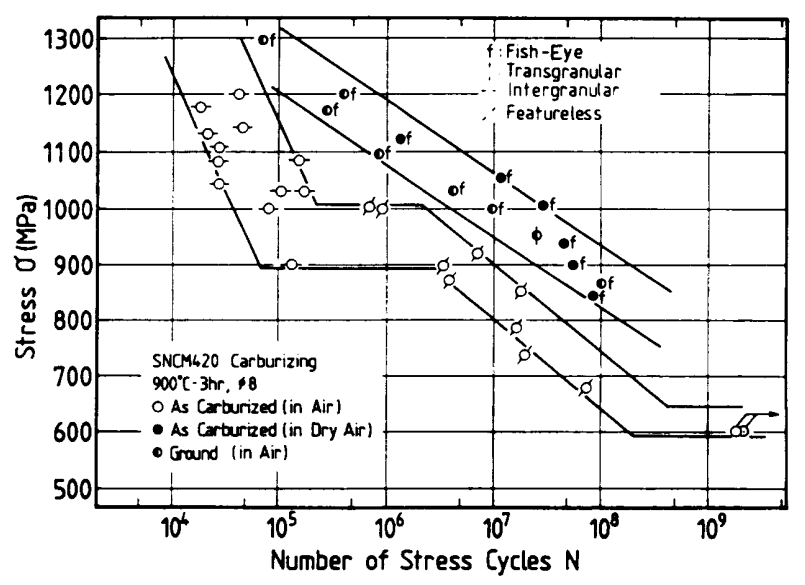

Fig. 9 S-N diagrams of carburized SNCM 420 steels 
fatigue limit of steel with surface microdefects, since the inclusions observed at the fracture origins are deemed as a microdefect and were very close to the specimen surface as shown in Fig. 10 ;

$$
\sigma_{w}=1.43\left(H_{v}+120\right) /(\sqrt{\text { area }})^{1 / 6}
$$

where $\sigma_{w}$ is the predicted fatigue limit ( $\left.\mathrm{MPa}\right), H_{v}$ is the Vickers hardness of the specimen $\left(\mathrm{kgf} / \mathrm{mm}^{2}\right)$, and $\sqrt{\text { area }}$ is the square root at the area $(\mu \mathrm{m})$ of the defect projected onto the plane normal to the direction of maximum tensile stress.

It is assumed that a spherical defect, whose diameter is equal to the maximum value (see Table 4) of sizes of inclusions observed at the fracture origins, is adjacent to the specimen surface. As the severest condition, the area in Eq. (1) can be taken, as shown in Fig. 11, in the same manner ${ }^{(6)}$ as done by Murakami et al. Using the area and the value of $H_{v}$ in Table 3, the fatigue limit can be predicted according to Eq. (1). The predicted fatigue limits are shown in Table 5. It is said that the values are sufficiently valid, according to the results of fatigue tests shown in Figs. 6 and 7.

The predicted fatigue limits of low-temperaturetempered specimens are nearly the same as those of high-temperature-tempered specimens. Therefore, it is said that the low-temperature-tempering is not necessarily effective as a method of improving the fatigue strength of low-alloy steel used for a long time under a cyclic stress.

Table 4 Maximum sizes $(\mu \mathrm{m})$ of defects observed at the fracture origins

\begin{tabular}{|c|c|c|c|c|}
\hline \multicolumn{2}{|c|}{ SCM435 } & \multirow{2}{*}{ SNCM439 } & SCM420 & SNCM420 \\
\cline { 1 - 2 } A & B & & & \\
\hline 38 & 36 & 46 & 93 & 70 \\
\hline
\end{tabular}

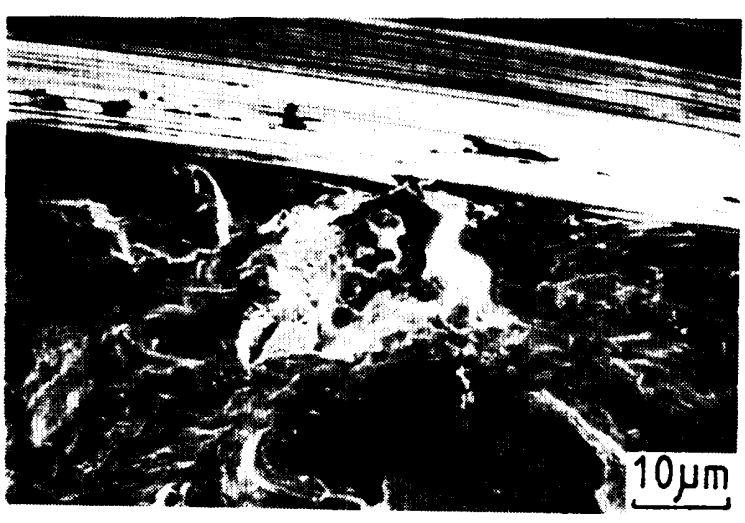

Fig. 10 An example of fish-eye-type fracture in lowtemperature-tempered steel (The inclusion is adjacent to the specimen surface)

\section{2 Carburized steels}

In general, formation of surface structure anomalies (internal oxides and nonmartensitic struotures) is inevitable for low-alloy steel carburized in generated gas, and it is well known that the surface structure anomalies cause ${ }^{(3),(4)}$ the reduction of fatigue strength. When the surface structure anomalies were removed by grinding off from the as-carburized specimens, the fatigue strengths were improved, as shown in Figs. 8 and 9. The S-N curves, however, dropped linearly even in the long life range over $10^{7}$ cycles, and no fatigue limits were found up to about $10^{9}$ cycles. Then, most of the fatigue fractures became fish-eye-type fractures (see mark $f$ in Figs. 8 and 9). These phenomena were similar to the case in the long life range of low-temperature-tempered steels described above, but the fracture origins were observed at a depth of about $1.0 \mathrm{~mm}$ because of both high hardness and residual compressive stress near the specimen surface.

Thus, the prediction of fatigue limit of ground-off specimens will be attempted, using the following equation $^{(6)}$ proposed by Murakami et al. for the prediction of fatigue limit of steel with subsurface microdefects and Eq. ( 1 ) given above.

$$
\sigma_{w}^{\prime}=1.56\left(H_{v}+120\right) /(\sqrt{\text { area }})^{1 / 6} \text {, }
$$

where $\sigma_{w}^{\prime}(\mathrm{MPa})$ is the fatigue limit at the location of the defect, while $H_{v}$ and $\sqrt{\text { area }}$ are the same as in Eq. (1).

At the fracture origins of ground-off specimens, fracture surfaces of intergranular and/or anomalistic microstructure are observed in addition to nonmetal. lic inclusions, as shown in Fig. 12. Although the mechanisms of formation are still unknown, these, like inclusions, will be deemed subsurface microdefects in the following discussions.

It is assumed that spherical defects, whose diameters are equal to the maximum value (see Table 4) of sizes of defects observed at the fracture origins, exist

Table 5 Predicted fatigue limits ( $\mathrm{MPa})$

\begin{tabular}{|c|c|c|c|c|}
\hline \multicolumn{2}{|c|}{ SCM435 } & \multirow{2}{*}{ SNCM439 } & SCM420 & SNCM420 \\
\cline { 1 - 2 } A & B & & & \\
\hline 511 & 534 & 520 & 606 & 647 \\
\hline
\end{tabular}

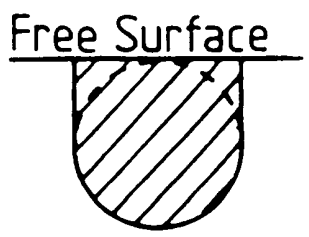

Fig. 11 Area of defect that is adjacent to specimen surface 


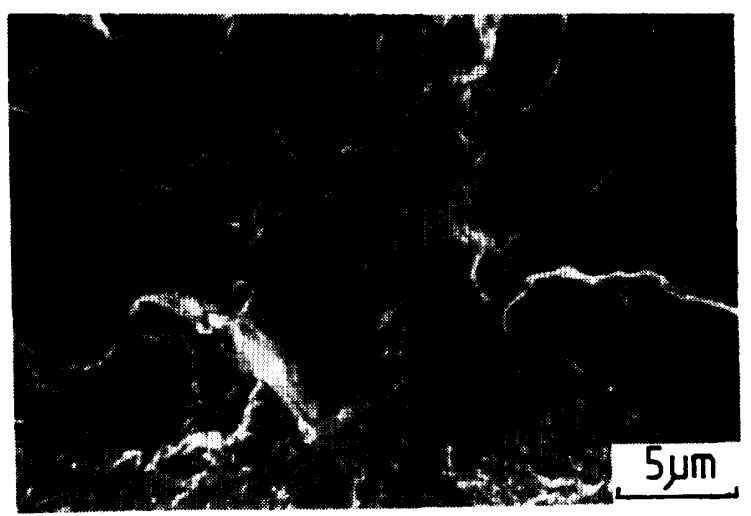

(a) The intergranular fracture surface observed at the fracture origin

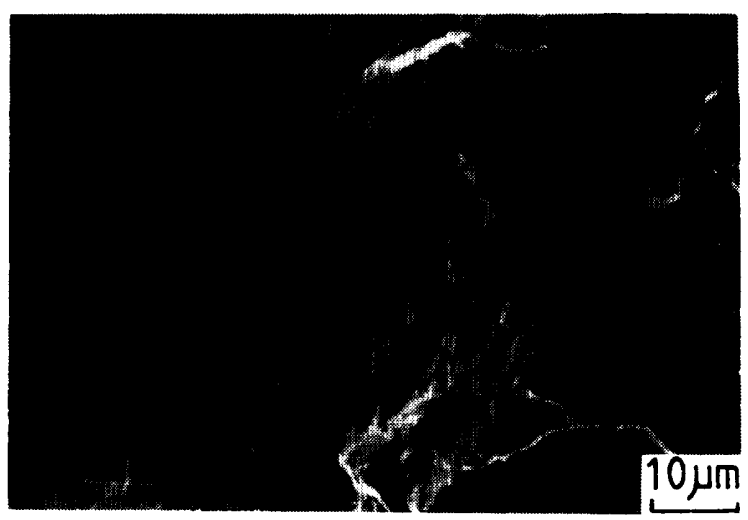

(b) The fracture surface of anomalistic structure observed at the fracture origin

Fig. 12 Examples of fracture surface near fracture origin of fish-eye-type fracture in carburized steel (in addition to inclusion)

at intervals of $0.1 \mathrm{~mm}$ from the specimen surface toward the internal direction. The area of maximum section of the assumed spherical defect is employed as the area in Eq. ( 2 ). On the other hand, the area in Eq. (1) is taken as shown in Fig. 11. The values of $H_{v}$ are determined from the hardness distributions shown in Fig. 1.

Using these values, the fatigue limit distributions can be predicted acoording to Eqs. (1) and (2). The predicted fatigue limit distributions are shown in Fig. 13. According to the applied bending stress distributions (solid lines in Fig. 15) adjacent to the predicted fatigue limit distributions, $606 \mathrm{MPa}$ and $647 \mathrm{MPa}$ are obtained as the predicted values of fatigue limits for the SCM 420 and the SNCM 420 ground-off specimens, respectively. On the basis of the results shown in Figs. 8 and 9, these values can be said to be sufficiently valid.

The predicted fatigue limits of ground-off specimens are not substantially different from the fatigue limits obtained in the as-carburized specimens. Consequently it is said that the elimination of surface structure anomalies is not very effective as a method of improving the fatigue strength of carburized steel used for a long time under cyclic loading. On the other hand, only the ground-off specimen to which cyclic stress of $1060 \mathrm{MPa}$ was applied did not fail up to 3.5 $\times 10^{8}$ cycles (see Fig. 8), though the applied cyclic stress was higher than the predicted fatigue limlt (606 $\mathrm{MPa})$. This is presumably due to a lack of defects that may become fracture origins. In such a case, fatigue limit nearly proportional to the hardness can be expected, but this should be considered an excep. tional case.

It has already been reported ${ }^{(3)(4)}$ that the fracture surface features at the fracture origin of an as-car-

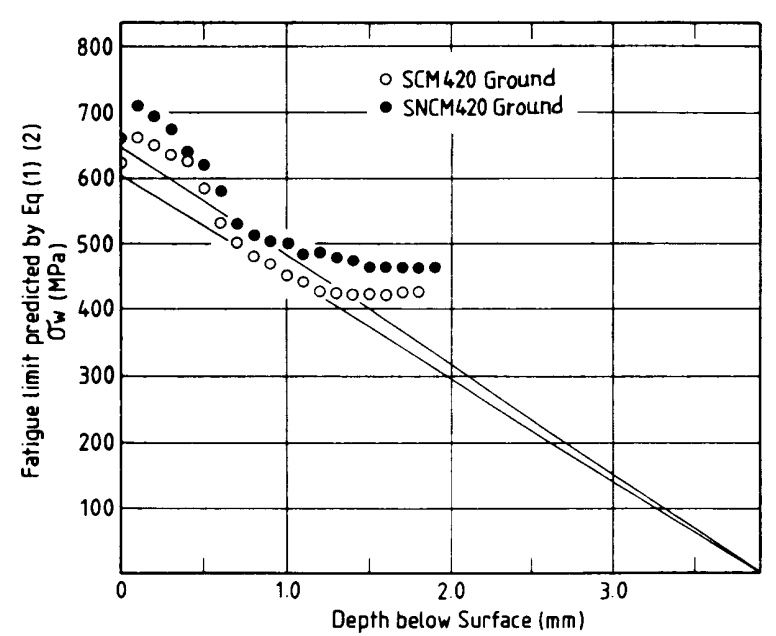

Fig. 13 Predioted fatigue limit distributions and applied bending stress distributions in carburized steels

burized specimen correspond very well to the presence of two knees recognized in the S-N diagram. Similar tendenoies were also found in this study. That 371 is, in the short life range up to the first knee, an intergranular fracture surface is observed at the fracture origin, followed by a transgranular fracture surface reflecting the microstructure (fracture surface in stage 2 a) as shown in Fig. 14(a). Since internal oxides could be seen on the intergranular fracture surface, it is clear that the intergranular fracture ocourred along the internal oxides. In the long life range over the second knee, on the other hand, a featureless facetlike fracture surface ${ }^{(3)}$ is observed instead of a transgranular fracture surface as shown in Fig. 14 (b). The difference in such a fracture surface at the fracture origin was also added to each test point in Figs. 8 and 9.

When fatigue tests of as-carburized specimens 


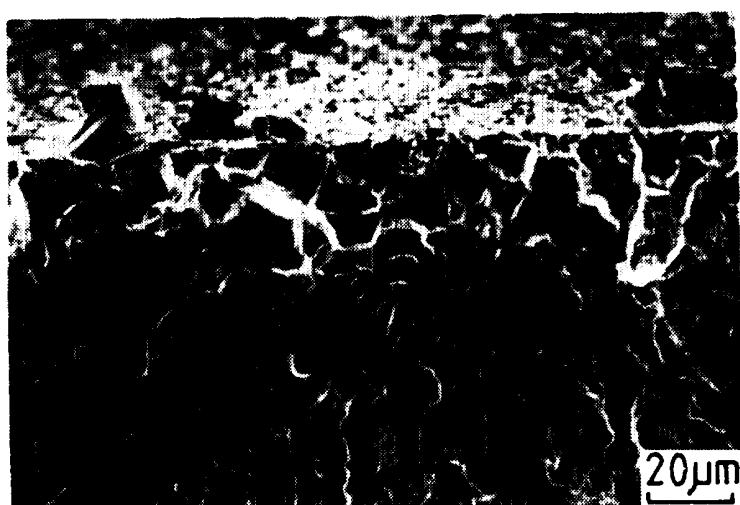

(a) in the short range $\left(<10^{5}\right.$ cycles $)$

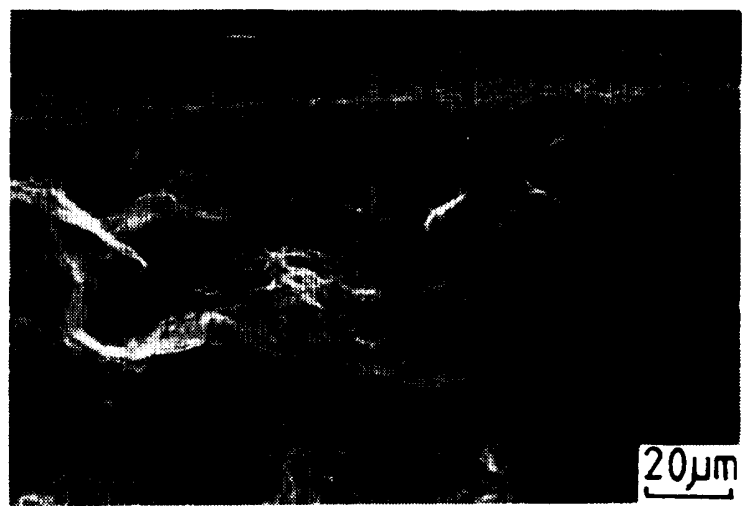

(b) in the long life range $\left(>10^{6}\right.$ cycles)

Fig. 14 Examples of fracture surface near fracture origin in carburized steel with surface structure anomalies (in the case tested in laboratory air)

were carried out in dry air, no featureless facetlike fracture surfaces were observed after the intergranular fracture surfaces and the fracture origins in the long life range over $10^{6}$ cycles shifted from surface to subsurface, as shown in Figs. 8 and 9. Also, the fatigue strengths became higher than those in laboratory air and coincided with those of ground-off specimens tested in laboratory air. On the other hand, the as-carburized specimens tested in laboratory air had the fatigue limits, though the values were markedly low (see Figs. 8 and 9). Then, it has been reported ${ }^{(3)}$ that the size of the featureless facetlike fracture surface increased with decreasing applied cyclic stress. Consequently, it is presumed that the featureless facetlike fracture surfaces observed in laboratory air were formed by the interaction between corrosion due to moisture in air and mechanical crack growth due to cyclic stress, and it is conoluded that this time-dependent type fracture induced the occurrence of the second knee and the reduction of fatigue strength in as-carburized speoimens with surface structure anomalies.

\section{Conclusions}

Rotating bending fatigue tests of JIS SCM 435 and SNCM 439 steels tempered at low temperatures $\left(150 \sim 200^{\circ} \mathrm{C}\right)$ or JIS SCM 420 and SNCM 420 steels carburized in generated gas were conducted in laboratory air and dry air, with particular attention paid to the long life range over $10^{7}$ cycles and the influence of moisture in air. The experimental results were investigated from the standpoint of these fractographies and the equations proposed by Murakami et al. for the prediction of fatigue limit with microdefects. The following conclusions have been obtained.

(1) In the case of low-temperature-tempered steels : (a ) The S-N diagrams revealed two knees on the curves, which dropped linearly even over $10^{7}$ cycles, and no fatigue limits were found up to $10^{9}$ cycles. (b) These phenomena resulted from the inclusions within the steels, which became the fracture origins. (c) The values $(510 \sim 530 \mathrm{MPa})$ of fatigue limits predicted for the specimens tempered at low temperatures were not substantially different from the values $(480 \sim 580 \mathrm{MPa})$ of fatigue limits obtained for the specimens tempered at high temperature $\left(600^{\circ}\right.$ C). (d) No influence of moisture in air was recognized in the fatigue strength characteristics.

(2) In the case of carburized steels: (a ) The S$\mathrm{N}$ diagrams of as-carburized specimens with surface structure anomalies revealed three knees on the curves; the fatigue limits were found over $10^{8}$ cycles, and the values $(500 \sim 600 \mathrm{MPa})$ were nearly the same as those $(480 \sim 580 \mathrm{MP}$ of high-temperature tempered SCM 435 and SNCM 439 steels. (b) Although the fatigue strengths of ground-off specimens without surface structure anomalles were improved, both knees and fatigue limits in the S-N diagrams were not found up to $10^{9}$ cycles. (c) The values $(600 \sim 650$ $\mathrm{MPa}$ ) of fatigue limits predicted for the ground-off specimens were not substantially different from the experimental values $(500 \sim 600 \mathrm{MPa})$ of fatigue limits obtained for the as-carburized specimens. (d) The influence of moisture in air was recognized in the long life range of as-carburized specimens, and it is presumed that the occurrence of the second knee and the reduction of fatigue strength were induced by the interaction between corrosion due to moisture in air and mechanical crack growth due to cyclic stress.

(3) From (1)-(c), (2)-(a) and (2)-(c) mentioned above, it can be said that neither lowtemperature tempering nor carburizing should be 
expected to yield good results as a method of improving fatigue strength of low-alloy steel used for a long time under cyclic loading.

\section{References}

(1) Nishijima, S., Statistical Fatigue Properties of Some Heat-Treated Steels for Machine Structural Use, ASTM STP 744 (1981), p. 75.

(2) Masuda, C., Nishijima, S. and Tanaka, Y., Relationship between Fatigue Strength and Hardness for High Strength Steels, Trans. Jpn. Soc. Mech. Eng., (in Japanese), Vol. 52, No. 476, A (1986), p. 847.

(3) Naito, T., Ueda, H. and Kikuchi, M., Fatigue Behavior of Carburized Steel with Internal Oxides and Nonmartensitic Microstructure near the Sur- face, Metall. Trans. A, Vol. 15 A (1984), p. 1431.

(4) Asami, K., Long-life Fatigue Strength of Tufftrided (Salt-Bath-Nitrided) and Carburized Steels, J. Jpn. Soc. Heat Treatment, (in Japanese), Vol. 25, No. 3 (1985), p. 123.

(5) Murakami, Y. and Endo, M., Effect of Hardness and Crack Geometry on $\Delta K_{\text {th }}$ of Small Cracks, The Behavior of Short Fatigue Cracks, ERF Pub., 1(1986), p.275, Mech. Eng. Pub. (Miller, K. J. and delos Rios, E. R. ed.)

(6) Murakami, Y., Kodama, S. and Konuma, S., Quantitative Evaluation of Effects of Nonmetallic Inclusions on Fatigue Strength of Steel, Trans. Jpn. Soc. Mech. Eng., (in Japanese), Vol. 54, No. 500, A (1988), p. 668. 